\title{
СТАНОВЛЕНИЕ И РАЗВИТИЕ АРХИТЕКТУРНОГО И ЭКСПОЗИЦИОННОГО ПРОСТРАНСТВ РОССИЙСКОГО ЭТНОГРАФИЧЕСКОГО МУЗЕЯ (1902-2017)
}

\begin{abstract}
Автор рассматривает историю становления архитектурного и экспозиционного пространств Российского этнографического музея, а также возможный сиенарий их развития. В статье освещаются вопросы создания музея, фондообразования, строительства комплекса зданий музея. Отдельное внимание уделяется проблеме недостаточности площуадей на протяжении всей истории музея и проектным решениям развития (расширения) архитектурного и экспозиционного пространств музея.
\end{abstract}

Ключевые слова: музей, архитектурное пространство, экспозиционное пространство, музейное пространство, Российский этнографический музей

Ссылка при цитировании: Давыдова Л.Н. Становление и развитие архитектурного и экспозиционного пространств Российского этнографического музея (1902-2017) // Вестник антропологии, 2021. № 3. С. 199-207.

В Российском этнографическом музее (современное название музея утверждено решением Правительства Российской Федерации в 1992 г. (Ботякова 2009: 11) собрано около 750 тыс. экспонатов, являющихся подлинными артефактами традиционной культуры 158 народов России и сопредельных стран Восточной Европы, Кавказа и Центральной Азии конца XVIII - начала XXI века (Шевченко, Саксонова, Каретникова 2013: 48). Отражена культура народов особой части Северной Евразии, ядром которой была Россия (Грусман 2014: 27). Датой создания музея принято считать 23 (10) января 1902 г. - день учреждения Этнографического отдела Русского музея императора Александра III (Ботякова 2009: 9; Грусман 2014: 19). В этот день Николаем II утверждены штаты отдела и открыто финансирование в государственном казначействе (Ботякова 2009: 10). Экспозиции открыты 3 июня 1923 г. с целью масштабного освещения быта всей России (Грусман 2014: 19; Александрова 2001: 33-34). Тем не менее, по другой версии, годом рождения музея считается 1934 г., когда в ходе реформы музейной сети СССР, начавшейся в 1925-1928 гг, Этнографический отдел Русского музея обретает статус отдельного института (Шевченко, Саксонова, Каретникова 2013: 47).

Однако архитектурное и экспозиционное пространства будущего самостоятельного музея первоначально формируются в 1900-1917 гг. Драматичная история строительства здания Этнографического и Памятного отделов Русского музея выдающимся русским архитектором В.Ф. Свиньиным (Шокуров-Свиньин 2015; Шокуров-Свиньин 2017 ) (1865-1939) наиболее полно исследована 3.А. Перскевич (Перскевич 2015).

Давыдова Любовь Николаевна - руководитель культурных программ, Региональная общественная организация «Чувашская национально-культурная автономия Санкт-Петербурга» (194358 Санкт-Петербург, поселок Парголово, ул. Николая Рубцова, 12). Эл. почта: lubow.david@yandex.ru 
Программа Этнографического отдела обсуждается на совещаниях при управляющем Русским музеем Великом князе Георгии Михайловиче 30 января, 13 февраля и 17 апреля 1901 г.. На этих совещаниях присутствуют будущий заведующий отделом Д.А. Клеменц, академики Н.П. Кондаков, В.И. Ламанский, А.Н. Пыпин, В.В. Радлов, А.И. Соболевский, А.А. Шахматов, вице-президент Императорской Академии художеств И.И. Толстой и др. Идеи, предложенные учеными и Д.А. Клеменцем, становятся базой, на которой идет дальнейшая разработка программы деятельности Этнографического отдела. В дальнейшем Д.А. Клеменц проводит эту работу уже как заведующий отделом вместе с хранителями Н.М. Могилянским, Е.А. Ляцким и К.А. Иностранцевым, принятыми в штат музея 10 января 1902 года (Шангина 1998: 98).

Весной 1901 г. строительная комиссия ходатайствует о приспособлении для музейных нужд Прачечного корпуса на углу Инженерной и Садовой улиц. Ходатайство удовлетворено, и к концу 1902 г. работы в бывшем Прачечном корпусе окончены. Размещены этнографические фонды, музейная канцелярия, мастерская архитектора, а также выделены несколько квартир для старших музейных служащих (Перскевич 2015: 67).

Разработкой концепции Этнографического отдела занимается в 1903 г. специальная комиссия Российской Академии наук, состоящая из академиков В.В. Радлова, С.Ф. Ольденбурга, В.В. Латышева. 4 октября 1903 г. направление работы Этнографического отдела Русского музея утверждено на общем заседании Академии наук (Шангина 1998: 99).

При создании Этнографического отдела в его деятельность закладывается база, характерная для объективной науки. Задача заключается в собрании единой по всей
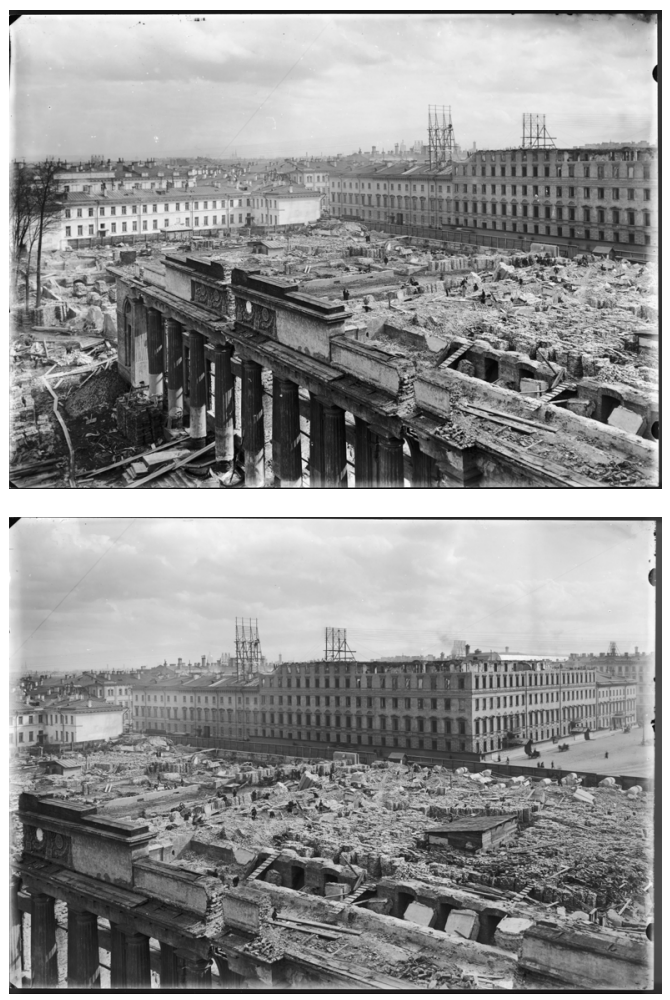

Рис. 1, 2. Этнографический музей стройплощадка (фото автора). стране научной коллекции предметов, характеризующейся достоверностью, полнотой и точностью (Грусман 2014: 19). Деятельность Этнографического отдела находится под покровительством императорской семьи. Николай II и другие представители династии Романовых передают на хранение в музей праздничную одежду, вышитые полотенца, золотошвейные изделия, ковры, подарочные подносы, посуду, парадное оружие и предметы культа. Вещи, связанные с Домом Романовых или принадлежавшие в прошлом частным собирателям, закладывают основу будущего собрания Российского этнографического музея (Ботякова 2009: 12). Поступления с 1902 по 1904 гг, осуществленные сотрудниками музея, и корреспондентами, в том числе именитыми учеными, составляют более 140 тысяч экспонатов. Фонд по культуре народов зарубежного Востока формируется еще с 1901 г. (Дмитриев 2012). Ведущую роль в фондообразовании отдела берет на себя Д.А. Клеменц (Шан- 
гина 1998: 107). Часть приобретений финансируется лично императором. Таким образом, архитектурное и экспозиционное пространства Этнографического отдела начинают формироваться еще до начала общестроительных работ в 1904-1908 гг. и до окончания строительства первой очереди здания Этнографического и Памятного отделов 15 октября 1910 г. (рис. 1, 2).

Из-за непригодности для музейных целей старых служебных флигелей возникает идея сооружения монументального здания для новых отделов музея. Совет Этнографического отдела изначально связывает экспозиционное пространство отдела с архитектурным: фасад по Инженерной улице отводится южной части России, левый флигель - западной, правый - восточной, фасад по линии Михайловского сада полярной окраине. Центр здания музея планируется занять русскими племенами (ВА ГРМ: Л. 27).

Не позднее 22 мая 1904 г. из трех окончательных вариантов застройки территории, предложенных В.Ф. Свиньиным, Николай II утверждает наиболее сокращенный вариант, указав ограничиться временно постройкой Памятного зала императора Александра III, лицевого корпуса Этнографического отдела по Инженерной улице, корпуса со стороны главного двора музея и более короткого корпуса, выходящего во двор канцелярии. Уменьшение площади застройки Русского музея почти в два раза происходит за счет именно Этнографического отдела, что влечет отказ от экспозиций «северных инородцев», «северной старой России» и Сибири. Таким образом, проблема недостаточности площадей возникает с момента учреждения Этнографического отдела и не разрешается со строительством здания Этнографического и Памятного отделов.

В конце 1920-х годов отказ от комплексной формы музея в пользу отраслевой и разные научные подходы (этногеографический, социологический) к организации экспозиционного пространства Этнографического отдела Государственного Русского музея не лишают его связи с архитектурным пространством, с которым оно интегрируется в общее, музейное пространство. В 1929 г. на первом этаже левого крыла здания размещается объединенная экспозиция по этнографии русских и финнов, над ними - залы украинцев и белорусов, в зале второго этажа - выставка по народам Саяно-Алтая, в правом крыле на втором этаже - экспозиции народов Кавказа и тюркоязычных народов Средней Азии, под ними на первом этаже правого крыла экспозиции кочевых тюркоязычных народов и народов Сибири и Дальнего Востока (Грусман, Дмитриев 2014: 9).

Несмотря на последствия революций 1917 г. (эвакуация экспонатов в Москву по распоряжению Временного правительства, разруха 1918-1919 гг.), наводнения 1924 г. (утрата части фондов) фонды Этнографического отдела продолжают пополняться. Тема развития архитектурного и экспозиционного пространств музея, в том числе через освоение территории, примыкающей к Михайловском саду, возникает неоднократно.

В 1931 г. обсуждается организация и структура Этнопарка на Крестовском острове у 2-го Елагина моста. Тогда же планируется строительство двух флигелей вокруг Памятного зала с одновременной ликвидацией опасных галерей вокруг него, подготовка нового хранилища резерва и усовершенствование хранительского оборудования (Грусман, Дмитриев 2014: 11).

В 1934 г. Приказом Народного Комиссара по Просвещению РСФСР от 13 марта 1934 года № 211 Этнографический отдел Государственного Русского музея выде- 
лен в самостоятельное юридическое лицо - культурный и научный центр - Государственный музей этнографии (Устав... Л. 2; Ботякова 2009: 11).

В блокадные годы (1941-1944) архитектурное и экспозиционное пространства музея получают значительные повреждения: в сентябре 1941 г. авиабомбой весом 250 кг разрушено восточное крыло главного корпуса, затем авиабомбой весом 200 кг повреждено западное крыло здания, 5 декабря 1941 г. 500-килограммовая бомба разрушает аванзал и часть Памятного зала, в 1942 г. неразорвавшейся авиабомбой разрушены перекрытия над Памятным залом, главный фасад здания сильно поврежден артиллерийскими снарядами, 4 бомбы и 15 снарядов попадают на территорию дворов музея и повреждают административный корпус и хозяйственные постройки (Первак 2015: 103-106). Однако научно-исследовательская работа музея полностью не остановлена.

К 1948 г. закончена реставрация части фондовых и экспозиционных помещений, в шести восстановленных залах музея организована первая послевоенная экспозиция «Народное искусство и национальная одежда славянских народов» (Первак 2015: 106). В 1948 г. Государственный музей этнографии получает почти все этнографическое собрание Государственного музея народов СССР в Москве, после чего официально переименован в Государственный музей этнографии народов СССР (Грусман, Дмитриев 2014: 7; Ботякова 2009: 11). Окончательно комплекс зданий музея восстановлен к 1956 г. (Первак 2015: 106).

К 1984 г. коллекции музея достигают объема в 450 тысяч предметов различных категорий (Грусман (рук. проекта) 2014: 20). Снова встает вопрос о расширении архитектурного и экспозиционного пространств музея. В 1984 г. по инициативе Государственного Русского музея разработано предпроектное предложение застройки участка на месте предполагавшегося ранее корпуса, которое включает снос пристроенного в 1929-1930 г. к северной стене объема Памятного зала четырехэтажного здания, используемого в качестве производственных мастерских Михайловского театра. Над разработкой соответствующего проекта трудятся советские и финские архитектурные бюро (Шевченко, Саксонова, Каретникова 2013: 47).

На заседании Коллегии Министерства культуры Российской Федерации 29 ноября 2000 года одобрена программа развития Российского этнографического музея на 2001-2010 гг., основным пунктом которой является решение вопроса о перемещении музейных фондов из аварийных подвальных помещений главного здания в новое фондохранилище. Строительство депозитария предполагается на участке, который в свое время планировал застроить В.Ф. Свиньин. В 2004 г. организован архитектурный конкурс, на котором отобран проект «Многофункциональный комплекс «Музей-Плаза» (архитектор Ю.И. Земцов). Предполагается, что в рамках государственно-частного партнерства инвестор «Корпорация С» выделяет 60\% построенного под фондохранилище, а оставшиеся 40\% занимает жилыми апартаментами категории VIP (Шевченко, Саксонова, Каретникова 2013: 47).

В 2013 г. по заказу ФГБУ «Северо-Западная дирекция по строительству, реконструкции и реставрации» Архитектурной мастерской Мамошина разработана Архитектурная концепция регенерации и завершения ансамбля Российского Этнографического музея и Государственного Русского музея (Архитектурная концепция фондохранилища для совместного использования Российским Этнографическим музеем и Государственным Русским музеем), рассмотренная 18 октября 2013 г. на Градостроительном совете. 
Значительное пополнение фондов музея с начала формирования архитектурного и экспозиционного пространств Российского этнографического музея актуализирует проблему недостаточности площадей. При масштабных временных выставках музей имеет возможность выставлять 18\% материала, хранящегося в его фондах (Шевченко, Саксонова, Каретникова 2013: 48). В настоящее время среднегодовой показатель экспонируемых коллекций составляет 2,5-5\%. Однако ни одно из проектных решений так и не реализовано. Расширение экспозиционного пространства музея достигается посредством проведения ремонтно-реставрационных работ в помещениях.

В 2017 г. ООО «Архитектурное бюро «ТРАДИЦИЯ» разработан проект Экспозиционного центра коллекций Российского этнографического музея, функционально представляющего собой комплекс для хранения, реставрации и экспозиции предметов коллекций музея (рис. 3, 4). Основанием для разработки проекта являются Задание КГИОП на проведение работ по сохранению объекта культурного наследия народов Российской Федерации от 2 августа 2016 г. № 2-13444/16-0-0, Градостроительный план участка от 21 сентября 2016 г. № RU7814500025153, Контракт от 11 июля 2016 г. № 1 /РЭМ с ФГБУК «Российский этнографический музей».

Приспособление под условия современного использования (реконструкция) здания бывших производственных мастерских СПб ГБУК «Санкт-Петербургский государственный академический театр оперы и балета им. М.П. Мусоргского - Михайловский театр», предназначенного для размещения Экспозиционного центра коллекций Российского этнографического музея, должно обеспечить решение проблем обеспечения организации современного хранения и реставрации

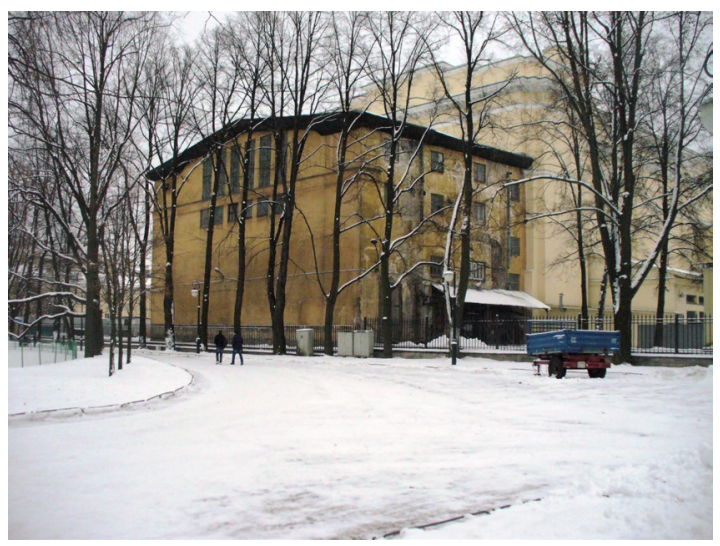

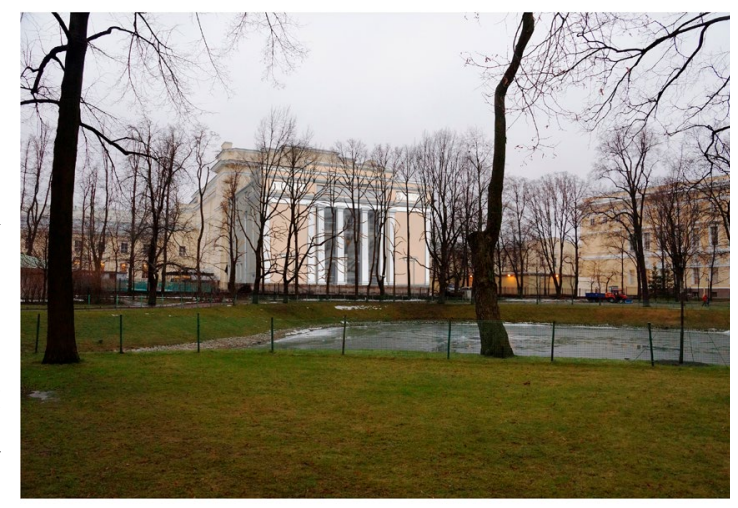

Рис. 2, 3. Этнографический музей стройплощяакка (фото автора). части коллекций музея, обеспечения музея дополнительными экспозиционными площадями.

В связи с предстоящими работами по реконструкции проектом предусматриваются мероприятия по сохранению объекта культурного наследия федерального значения - здания Российского этнографического музея, к которому непосредственно примыкает реконструируемое здание, и объекта культурного наследия федерального значения «Сад Михайловский с прудом», на территории которого здание находится.

Реконструируемое здание (максимальные размеры здания $28,26 \mathrm{M} \times 18,66 \mathrm{M}$, наибольшая высота здания от уровня земли до конька составляет 17,96м, площадь застройки с 
учетом крыльца с навесом 566,0 м²) не является объектом культурного наследия, но расположено в границах объекта культурного наследия федерального значения «Сад Михайловский с прудом» и пристроено к стене объекта культурного наследия федерального значения «Корпус Этнографического отдела Русского музея (Этнографический музей)», входящих в ансамбль «Дворец Великого князя Михаила Павловича (Русский музей Императора Александра III). На момент проектирования не эксплуатируется.

Конструктивной особенностью реконструируемого здания является то, что конструкции фундамента и конструкции стен разделены с примыкающим зданием музея деформационным швом, тогда как конструкции межэтажных перекрытий, фермы покрытия и несущие элементы лестницы деформационного шва не имеют и опираются непосредственно на кирпичную кладку стены здания музея - объекта культурного наследия федерального значения. То есть собственной стены на отдельном фундаменте, выстроенной вдоль наружной стены музея реконструируемое здание не имеет, и при данных сложившихся условиях работы создаются воздействия, оказывающие неблагоприятное влияние на несущие конструкции перекрытий, крыши и лестницы, а также на смежную стену здания музея.

Обследованием кирпичной северной стены на бутовом фундаменте Памятного зала Российского этнографического музея, к которой примыкает реконструируемое здание, не выявлено каких-либо существенных конструктивных дефектов. Имеющиеся исторические материалы свидетельствуют о том, что на этапе строительства здания Этнографического отдела в этой стене на уровне первого этажа были устроены дверные проемы, видимо, в целях обеспечения потенциальной возможности реализации первоначального замысла автора проекта, касающегося строительства нереализованного северного корпуса музея. Для подтверждения факта наличия исторических проемов в северной наружной стене здания Российского этнографического музея, к которой примыкает реконструируемое здание, помимо изучения архивных документов, выполнены два контрольных вскрытия штукатурного слоя стены. По результатам вскрытий установлено, что в стене ранее действительно выполнено два проема. На момент обследования проемы со стороны реконструируемого здания заложены легкобетонными блоками и кирпичом, оштукатурены и окрашены, а в помещениях первого этажа соседнего здания, в хранилище музея, на месте проемов устроены ниши, приспособленные для хранения музейных материалов.

В связи с необходимостью организации обязательной функциональной связи между помещениями существующего музея и помещениями реконструируемого здания в примыкающей стене музея, в створе боковых обходных коридоров Памятного зала, раскрываются два существовавших, предусмотренных при строительстве, но заложенных в ходе эксплуатации здания дверных проема. Обходные коридоры зала не имеют ценной исторической отделки, и работы по раскрытию проемов не затронут выявленных предметов охраны зала. В проемах устанавливаются деревянные филенчатые дверные заполнения, выполненные по историческим аналогам.

Доступ посетителей в экспозиции реконструируемого здания осуществляется только в составе экскурсионных групп, со стороны главного входа в музей с Инженерной улицы через обходные коридоры Памятного зала и раскрываемые исторические проемы. Аналогичным способом попадают в здание сотрудники музея. Наружные двери реконструируемого здания используются только для эвакуации посетителей и сотрудников в случае пожара. 
Реконструкция здания предусматривает частичный демонтаж основных его конструкций и воссоздание четырехэтажного бесчердачного надземного объема здания с сохранением существующих горизонтальных габаритов, высотных отметок боковых карнизов и конька кровли и изменением его архитектурного облика, учитывающим принцип стилистического соответствия нового образа сложившейся окружающей застройке. Также проектом предусматривается организация объема эксплуатируемого подвального этажа путем устройства железобетонного кессона на свайном основании с сохранением и усилением существующих фундаментов под наружными стенами здания.

На первом этаже реконструируемого здания, высотная отметка пола которого соответствует отметке пола обходных коридоров Памятного зала, располагаются помещения вестибюльной группы для посетителей, двухсветное экспозиционное пространство для установки габаритных экспонатов и помещения для хранения экспонатов музея (фондов). Высота помещений первого этажа - 3,6 м. Второй и третий этажи предполагают размещение экспозиционных площадей, помещений для хранения экспонатов и кабинетов хранителей. Высота помещений второго и третьего этажей 3,6 м. Четвертый этаж предназначен для размещения фондов хранения экспонатов и кабинетов хранителей. Высота помещений четвертого этажа, частично образованного плоскостями совмещенной скатной кровли, варьируются от 2,44 м до 4,46 м.

Вертикальная связь между этажами здания осуществляется посредством двух лестниц, имеющих выход непосредственно на улицу, а также двух лифтов разного функционального назначения.

Таким образом, архитектурное и экспозиционное пространства Российского этнографического музея начинают формироваться с момента учреждения Этнографического отдела Русского музея императора Александра III в 1902 г., еще до начала общестроительных работ в 1904-1908 гг. и до окончания строительства здания музея в 1910 г. Проблема недостаточности площадей возникает с момента учреждения Этнографического отдела и не разрешается со строительством здания музея. Расширение экспозиционного пространства музея достигается посредством проведения ремонтно-реставрационных работ в помещениях. Музейное пространство Российского этнографического музея претерпевает качественные и структурные изменения, пополняются фонды музея, однако его количественные характеристики остаются прежними. В этом смысле архитектурное и экспозиционное пространства Российского этнографического музея требуют развития. Реализация проекта Экспозиционного центра коллекций Российского этнографического музея, разработанного в 2017 г. ООО «Архитектурное бюро «ТРАДИЦИЯ», в современных условиях является наиболее реалистичным сценарием развития архитектурного и экспозиционного пространств музея.

\section{Источники и материалы}

ВА ГРМ - Ведомственный архив Государственного российского музея. Ф. ГРМ (1). Оп. 1. Ед. хр. 272.

Устав - Устав Федерального государственного бюджетного учреждения культуры «Российский этнографический музей» (новая редакция) (утвержден приказом Министерства культуры Российской Федерации от 1 июня 2011 года № 596). М., 2011. 24 л. 


\section{Научная литература}

Александрова Л.К. (авт.-сост.) Российский этнографический музей 1902-2002. СПб.: АО Славия, 2001. $278 \mathrm{c}$.

Ботякова О.А. Российский этнографический музей: путеводитель. СПб.: АО Славия, 2009. 224 с.

Грусман В.М., Дмитриев В.А. Из истории Российского этнографического музея: к 80-летию обретения самостоятельности // Музей. Традиции. Этничность, 2014. № 1 (5). С. 6-24.

Грусман В.М. (рук. проекта) Народы России. XVIII - начало XX века. СПб.: АО Славия, 2014. 619 с.

Дмитриев С.В. Фонд Этнографического отдела Русского музея по культуре народов зарубежного Востока: история формирования и судьба (1901-1930-е гг.). СПб.: Филологический факультет СПбГУ, 2012. 832 с.

Первак В.Э. Реставрация здания Российского этнографического музея // Музей. Традиции. Этничность, 2015. № 1 (7). С. 103-107.

Перскевич 3.А. Русский музей императора Александра III: здание для Этнографического и Памятного отделов. 1900-1917 // Музей. Традиции. Этничность, 2015. № 1 (7). С. 64-75.

Шангина И.И. Д.А. Клеменц и Этнографический отдел Русского музея императора Александра III // Пигмалион музейного дела в России (К 150 -летию со дня рождения Д.А. Клеменца) / под ред. И.В. Дубова. СПб.: Издательство Лань, 1998. С. 95-110.

Шевченко Э., Саксонова Е., Каретникова Е. Спираль истории. Вестник. Зодчий. 21 век, 2013. № 4 (49): 46-51.

Шокуров-Свиньин А.А. Неизвестные страницы биографии В.Ф. Свиньина // Музей. Традиции. Этничность, 2015. № 1 (7). С. 92-102.

Шокуров-Свиньин А.А. Архитектор Василий Федорович Свиньин: неизвестные страницы биографии и творчества (1865-1939 гг.) // Клио, 2017. № 3 (123). С. 145-155.

Davydova, Liubov $N$.

\section{Formation and Development of Architectural and Expositional Spaces of the Russian} Museum of Ethnography (1902-2017)

DOI: $10.33876 / 2311-0546 / 2021-3 / 199-207$

The author examines the history of the architectural and exhibition spaces of the Russian Museum of Ethnography and a possible scenario for their development. The article discusses the history of the museum's creation, the fund-raising, construction of the museum buildings. Special attention is paid to the problem of insufficient space throughout the museum's history and the projects for the expansion of its architectural and exhibition spaces.

Keywords: museum, architectural space, expositional space, museum space, Russian Museum of Ethnography

For Citation: Davydova, L.N. 2021. Formation and Development of Architectural and Expositional Spaces of the Russian Museum of Ethnography (1902-2017). Herald of Anthropology (Vestnik Antropologii) 3: 199-207.

Author info: Davydova, Liubov N. - head of cultural programs, Regional Public Organization «Chuvash National-Cultural Autonomy of St. Petersburg» (194358, St. Petersburg, RF). E-mail: lubow.david@yandex.ru 


\section{References}

Aleksandrova, L.K., ed. 2001. Rossiiskii etnograficheskii muzei 1902-2002 [Russian Museum of Ethnography 1902-2002]. St. Petersburg: AO Slaviia.

Botiakova, O.A. 2009. Rossiiskii etnograficheskii muzei: putevoditel' [Russian Museum of Ethnography: guidebook]. St. Petersburg: AO Slaviia.

Grusman, V.M. and V.A. Dmitriev. 2014. Iz istorii Rossiiskogo etnograficheskogo muzeia: k 80-letiiu obreteniia samostoiatel'nosti [From the history of the Russian Museum of Ethnography: to the 80th anniversary of gaining independence]. Muzei. Traditsii. Etnichnost' 1 (5): 6-24.

Grusman, V.M., ed. 2014. Narody Rossii. XVIII - nachalo XX veka [Peoples of Russia. XVIII early XX century]. St. Petersburg: AO Slaviia.

Dmitriev, S.V. 2012. Fond Etnograficheskogo otdela Russkogo muzeia po kul'ture narodov zarubezhnogo Vostoka: istoriia formirovaniia i sud'ba (1901-1930-egg.) [Fund of the Ethnographic Department of the Russian Museum for the Culture of the Peoples of the Foreign East: the history of formation and fate (1901-1930s)]. St. Petersburg: Filologicheskii fakul'tet SPbGU.

Pervak, V.E. 2015. Restavratsiia zdaniia Rossiiskogo etnograficheskogo muzeia [Restoration of the building of the Russian Museum of Ethnography]. Muzei. Traditsii. Etnichnost'1 (7): 103-107.

Perskevich, Z.A. 2015. Russkii muzei imperatora Aleksandra III: zdanie dlia Etnograficheskogo i Pamiatnogo otdelov. 1900-1917 [Russian Museum of Emperor Alexander III: building for the Ethnographic and Memorial Departments. 1900-1917]. Muzei. Traditsii. Etnichnost' 1 (7): 64-75.

Shangina, I.I. 1998. D.A. Klements i Etnograficheskii otdel Russkogo muzeia imperatora Aleksandra III [D.A. Klements and the Ethnographic Department of the Russian Museum of Emperor Alexander III]. In Pigmalion muzeinogo dela v Rossii (K 150-letiiu so dnia rozhdeniia D.A. Klementsa), edited by I.V. Dubov. St. Petersburg: Izdatel'stvo Lan': 95-110.

Shevchenko, E., E. Saksonova, and E. Karetnikova. 2013. Spiral' istorii [Spiral of history]. Vestnik. Zodchii. 21 vek 4 (49): 46-51.

Shokurov-Svin'in, A.A. 2015. Neizvestnye stranitsy biografii V.F. Svin'ina [Unknown Pages of Vasily Svinyin' Biography]. Muzei. Traditsii. Etnichnost' 1 (7): 92-102.

Shokurov-Svin'in, A.A. 2017. Arkhitektor Vasilii Fedorovich Svin'in: neizvestnye stranitsy biografii i tvorchestva (1865-1939) [Architect Vasiliy Fedorovich Svinin: unknown pages of biography and work (1865-1939)]. Klio 3 (123): 145-155. 